\title{
Prostate cancer screening with prostate-specific antigen (PSA) test: a clinical practice guideline
}

\author{
Kari A O Tikkinen, ${ }^{12}$ Philipp Dahm, ${ }^{3}$ Lyubov Lytvyn, ${ }^{4}$ Anja F Heen, ${ }^{5}$ Robin W M Vernooij, ${ }^{6}$ \\ Reed A C Siemieniuk, ${ }^{4}$ Russell Wheeler, ${ }^{7}$ Bill Vaughan, ${ }^{8}$ Awah Cletus Fobuzi, ${ }^{9} 10$ \\ Marco H Blanker, ${ }^{11}$ Noelle Junod, ${ }^{12}$ Johanna Sommer, ${ }^{13}$ Jérôme Stirnemann, ${ }^{14}$ Manabu Yoshimura, ${ }^{15}$ \\ Reto Auer, ${ }^{16}{ }^{17}$ Helen MacDonald, ${ }^{18}$ Gordon Guyatt, ${ }^{4}$ Per Olav Vandvik, ${ }^{5}$ Thomas Agoritsas ${ }^{4} 1419$
}

\section{Full author details can be found at the end of the article \\ Correspondence to: KA O Tikkinen kari.tikkinen@gmail.com Cite this as: $B M / 2018 ; 362: k 3581$ doi: 10.1136/bmj.k3581}

This BMJ Rapid Recommendation article is one of a series that provides clinicians with trustworthy recommendations for potentially practice changing evidence. BMJ Rapid Recommendations represent a collaborative effort between the MAGIC group (http:// magicproject.org/) and The $B M J$. A summary is offered here and the full version including decision aids is on the MAGICapp (https://app.magicapp.org), for all devices in multilayered formats. Those reading and using these recommendations should consider individual patient circumstances, and their values and preferences and may want to use consultation decision aids in MAGICapp to facilitate shared decision making with patients. We encourage adaptation and contextualisation of our recommendations to local or other contexts. Those considering use or adaptation of content may go to MAGICapp to link or extract its content or contact The BM/ for permission to reuse content in this article.
What is the role of prostate-specific antigen (PSA) screening in prostate cancer? An expert panel produced these recommendations based on a linked systematic review. ${ }^{1}$ The review was triggered by a large scale, cluster randomised trial on PSA screening in men without a previous diagnosis of prostate cancer published in 2018 (box 1). ${ }^{2}$ It found no difference between one-time PSA screening and standard practice in prostate cancer mortality but found an increase in the detection of low risk prostate cancer after a median follow-up of 10 years.

Although the results of this study suggest screening is not worthwhile, several guidelines advocate offering screening in some cases. The study was much larger than previous studies, and existing trials had published more extended follow-up results, and the BMJ Rapid Recommendations team felt these merited a new appraisal of

\section{WHAT YOU NEED TO KNOW}

- PSA testing has increased the number of men diagnosed with and treated for prostate cancer, but many of these men would never have experienced any symptoms or death from prostate cancer

- This guideline makes a weak recommendation against offering systematic PSA screening based on an updated systematic review. The recommendation is weak because there may be a small, though uncertain, benefit of screening on prostate cancer mortality

- Men who place more value on avoiding complications from biopsies and cancer treatment are likely to decline screening. In contrast, men who put more value in even a small reduction of prostate cancer mortality (such as men at high baseline risk because of family history or African descent, or those concerned to rule out the diagnosis) may opt for screening

- Shared decision making is needed for men considering screening to make a decision consistent with their individual values and preferences. However, clinicians need not feel obligated to systematically raise the issue of PSA screening with their patients the body of evidence. This guideline aims to promptly and transparently translate potentially practice-changing evidence to usable recommendations for clinicians and patients, based on the GRADE framework and following standards for trustworthy guidelines.

The panel suggests against systematic PSA screening (weak recommendation). The panel members judged that most men will decline screening because the benefit is small and uncertain and there are clear harms. However, there is likely considerable variation in values and preferences. Men with family history of prostate cancer, African descent or of lower socioeconomic status, having higher baseline risk of prostate cancer death, may be more likely to choose PSA screening. Shared decision-making is needed for men considering screening.

Box 2 shows all of the articles and evidence linked in this Rapid Recommendation package. The main infographic provides an overview of the absolute benefits and harms of PSA screening. The table at the end of the article shows any evidence that has emerged since the publication of this guideline.

\section{Current practice}

Prostate cancer is one of the most common cancers in men and is the leading cause of cancer death in 24 countries, ranking eighth globally, sixth in high income countries, and 12th in low income countries. ${ }^{3}$ Prostate cancer screening is with a PSA blood test. A raised PSA level can be a sign of prostate cancer but can also occur

Box $1 \mid$ Results of the CAP Randomized Clinical Trial ${ }^{2}$ This cluster-randomised trial of 419582 British men was published in March 2018. After a median follow-up of 10 years, there was no significant difference in prostate cancer-specific mortality in men receiving care by general practices randomised to a single PSA screening intervention compared with men receiving care by practices randomised to standard practice without screening. The detection of low risk prostate cancer cases was higher in the PSA screening group. Although the trial had limitations, such as low adherence to PSA testing in the intervention arm (36\%) and a follow-up of only 10 years, its findings do not support the use of single PSA testing for population based screening.

The Rapid Recommendations executive felt this new study-taken together with extended follow-up data from existing trials-required a new appraisal of the body of evidence for patients and clinicians. 

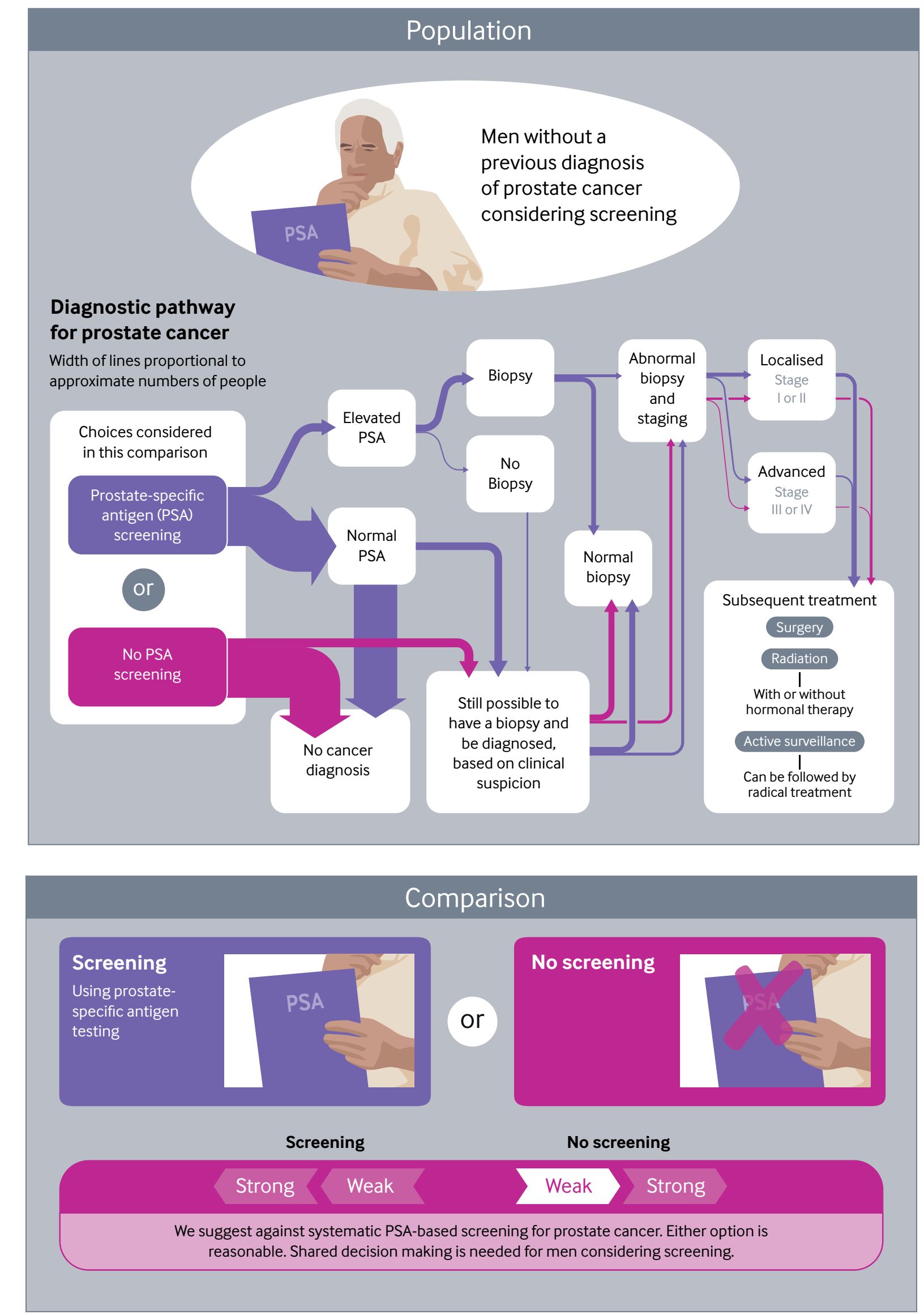

Disclaimer: This infographic is not a validated clinical decision aid. This information is provided without any representations, conditions or warranties that it is accurate or up to date. BMJ and its licensors assume no responsibility for any aspect of treatment administered with the aid of this information. Any reliance placed on this information is strictly at the user's own risk. For the full disclaimer wording see BMJ's terms and conditions: 


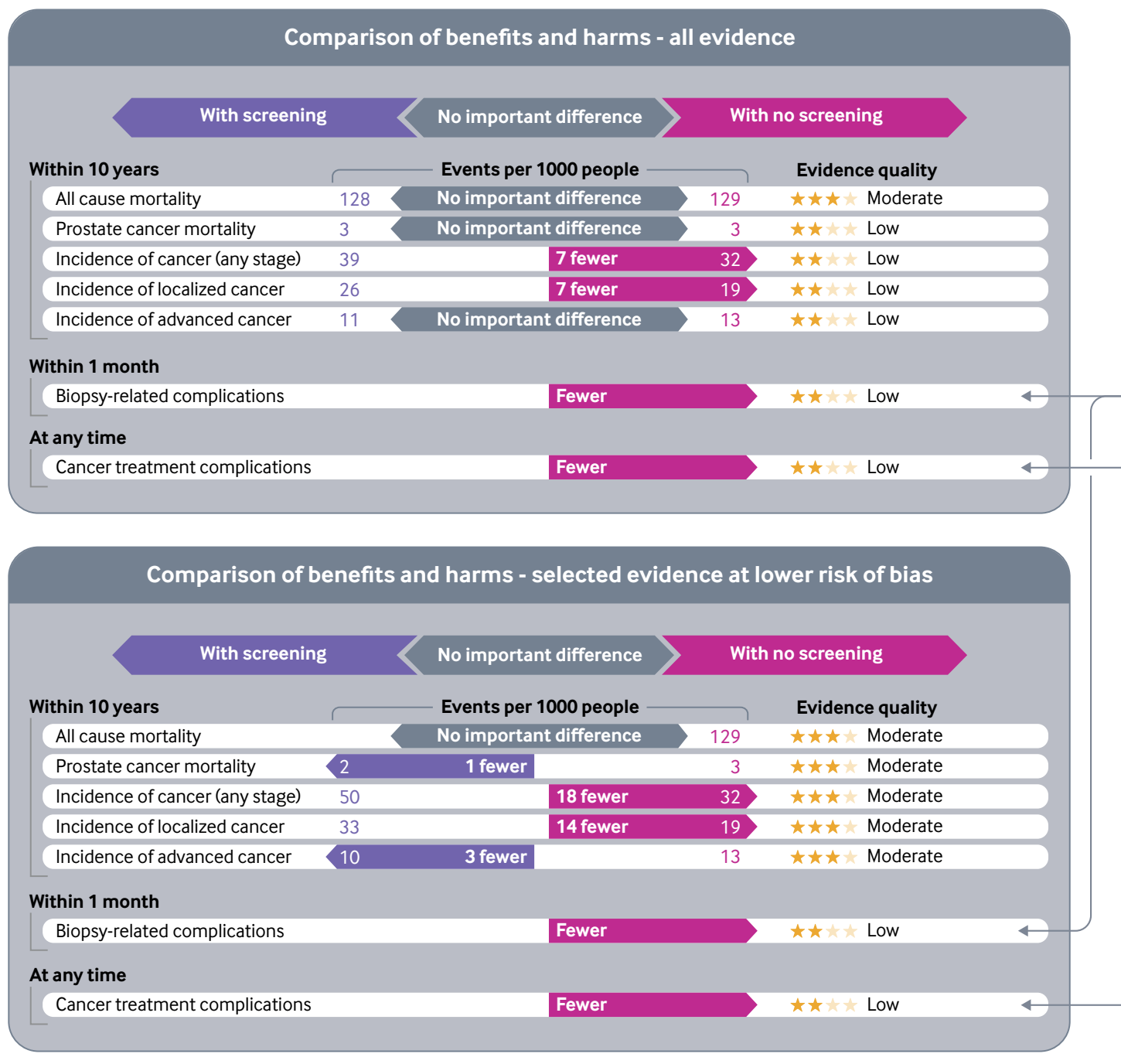
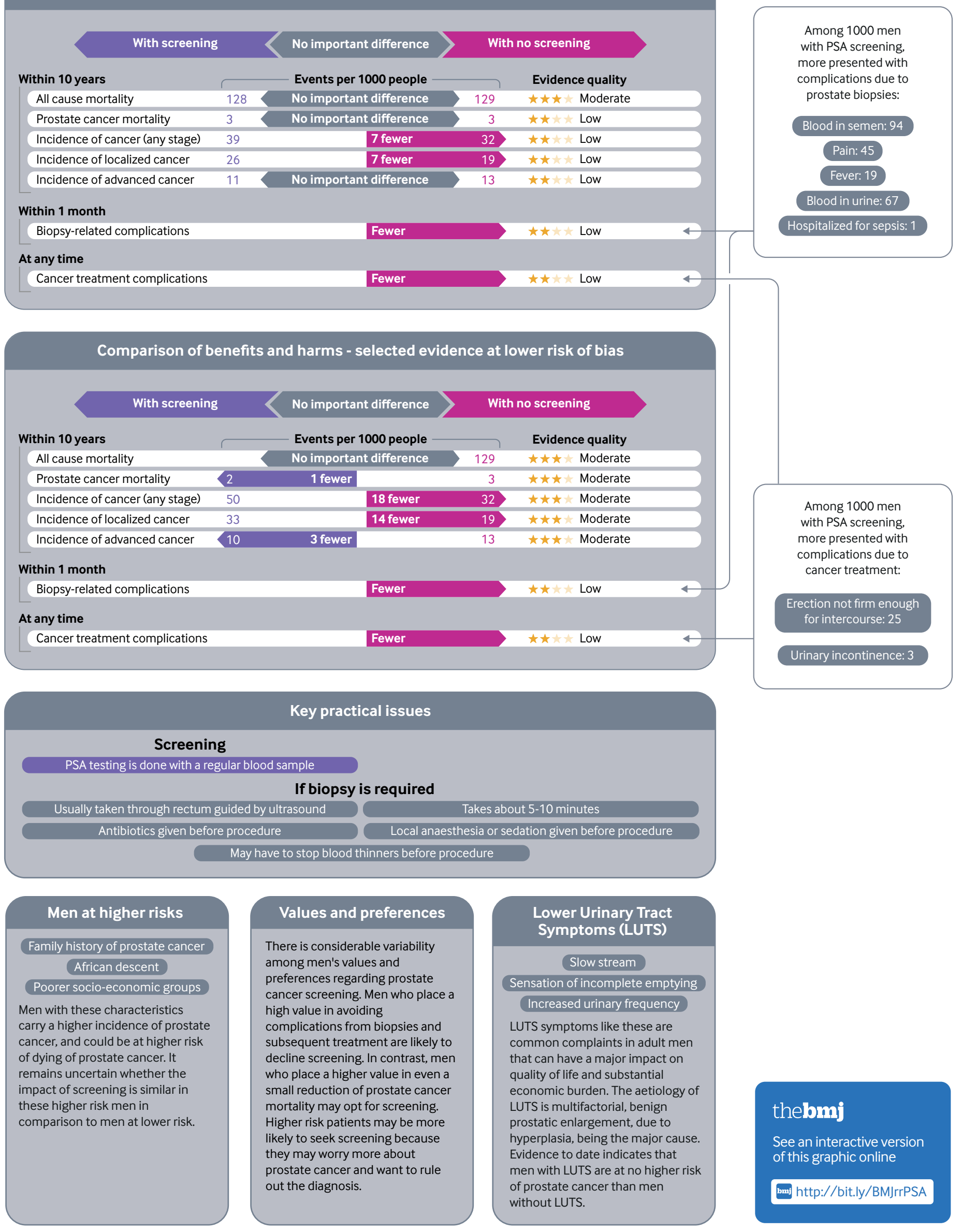

Values and preferences

There is considerable variability among men's values and preferences regarding prostate cancer screening. Men who place a high value in avoiding

complications from biopsies and subsequent treatment are likely to decline screening. In contrast, men who place a higher value in even a small reduction of prostate cancer mortality may opt for screening. Higher risk patients may be more likely to seek screening because they may worry more about prostate cancer and want to rule out the diagnosis.

\begin{tabular}{l} 
Lower Urinary Tract \\
Symptoms (LUTS) \\
\multicolumn{1}{c|}{ Slow stream } \\
Sensation of incomplete emptying \\
Increased urinary frequency \\
LUTS symptoms like these are \\
common complaints in adult men \\
that can have a major impact on \\
quality of life and substantial \\
economic burden. The aetiology of \\
LUTS is multifactorial, benign \\
prostatic enlargement, due to \\
hyperplasia, being the major cause. \\
Evidence to date indicates that \\
men with LUTS are at no higher risk \\
of prostate cancer than men \\
without LUTS.
\end{tabular}


Box 2 | Linked articles in this BMJ Rapid Recommendation cluster

- Tikkinen KAO, Dahm P, Lytvyn L, et al. Prostate cancer screening with prostate-specific antigen (PSA) test: a clinical practice guideline. BMJ 2018:362:k3581. doi:10.1136/bmj.k3581

- Summary of the results from the Rapid Recommendation process

- Ilic D, Djulbegovic M, Jung JH, et al. Prostate cancer screening with prostate-specific antigen (PSA) test: a systematic review and meta-analysis. $B M$ J 2018:362:k3519. doi:10.1136/bmj.k3519

- Systematic review and meta-analysis of all available randomised trials that assessed PSA based screening for prostate cancer

- Vernooij RWM, Lytvyn L, Pardo-Hernandez H, et al. Values and preferences of men for undergoing prostate-specific antigen screening for prostate cancer: a systematic review. BMJ Open 2018;0:e025470. doi:10.1136/bmjopen-2018-025470

- Systematic review of the values and preference of men considering PSA screening

- MAGICapp (https://app.magicapp.org/public/ guideline/n32gkL)

- Expanded version of the results with multilayered recommendations, evidence summaries, and decision aids for use on all devices

due to a non-cancerous enlargement or inflammation of the prostate. ${ }^{4}$ Many men have a raised PSA level without having cancer (that is, false positive results). Conversely, a substantial number of men with a low PSA level will subsequently be diagnosed with prostate cancer (false negative results).

\section{Investigations after raised PSA}

If PSA is raised, the test is usually repeated. Men with persistently elevated PSA levels typically undergo a transrectal, ultrasound-guided, core-needle biopsy of the prostate to test for prostate cancer (see main infographic). If cancer is detected in the biopsied tissue, management options include surgery, radiation therapy, hormonal treatment, active surveillance, or watchful waiting. Diagnostic imaging studies such as ultrasonography, magnetic resonance imaging (MRI), bone scan, and computed tomography, are often also performed, especially in men presenting with higher risk disease, to check for disease spread.

\section{Screening controversy}

For many reasons, PSA screening remains controversial. Advocates often base their opinions on the European Randomised study of Screening for Prostate Cancer (ERSPC), which suggests that screening may reduce the long term risk of prostate cancer-specific mortality by at least $9 \%$ (relative reduction). ${ }^{5}$ They also note that substantial observational evidence indicates a reduction in advanced disease and reduction in prostate cancer mortality, which they attribute to the introduction of PSA screening. ${ }^{6}$ Opponents of PSA screening highlight the indolent natural course of prostate cancer, citing systematic reviews that reported little or no impact of PSA screening on overall and prostate cancer-specific mortality. ${ }^{7}$ Opponents also

\section{HOW THIS RECOMMENDATION WAS CREATED}

Our international panel included patient partners (men at risk of prostate cancer), general practitioners, general internists, urologists, epidemiologists, methodologists, and statisticians. They determined the scope of the question that the recommendation should address and what outcomes are most important to patients considering screening.

No person had financial conflicts of interest; intellectual and professional conflicts were minimised and managed (see appendix 1 on bmj.com).

The panel identified eight critical outcomes needed to inform the recommendations: all-cause mortality; prostate cancer mortality; incidence of prostate cancer diagnoses (all stages); incidence of localised cancer (stage I and II); incidence of advanced cancer (stage III and IV); complications from biopsies (such as bleeding, pain, infections, and hospital readmissions), complications from prostate cancer treatment (such as urinary incontinence and erectile dysfunction); and quality of life. The panel also identified three additional patient-important outcomes: false positive rates (men with elevated PSA levels who will have negative biopsy); false negative rates (men with a normal PSA result who will subsequently be diagnosed with cancer), and the anxiety and uncertainty related to concerns about having prostate cancer. The panel asked that potential subgroups effects be explored according to age, screening interval, family history, being of African descent, and being of lower socioeconomic level. They also asked for a sensitivity analysis of the effect of screening restricted to trials at lower risk of bias.

To inform the recommendation, the panel members requested two systematic reviews, on the following questions:

- What are the benefits and harms of PSA screening versus no screening? ${ }^{1}$

-What evidence describes the values and preference of men considering PSA screening ? $^{29}$

Two parallel teams conducted these systematic reviews, which are linked to this publication.

The panel met to discuss the evidence and formulate a recommendation. They followed the $B M J$ Rapid Recommendations procedures for creating a trustworthy recommendation, ${ }^{43}$ including use of the GRADE approach to interpret the evidence and create recommendations (see appendix 2 on bmj.com) ${ }^{44}$ The panel considered the balance of benefits, harms, and burdens of PSA screening; the quality of the evidence for each outcome; and typical and expected variations in patient values and preferences, as well as feasibility and acceptability. Recommendations can be strong or weak, for or against a course of action. The recommendations take a patient-centred perspective which de-emphasises public health, societal, and health payer point of view.

suggest that the harms and burden from overdiagnosis and overtreatment resulting in unnecessary prostate biopsies and impaired urinary, sexual, and bowel function as side effects of surgery or radiation therapy outweigh the uncertain and modest benefits.

\section{Current guidelines on PSA testing}

Guidelines vary in their recommendations on PSA testing (see table 1). The Canadian Task Force on Preventive Health Care recommends against PSA screening for men aged 55 to 69 years. ${ }^{8}$ However, the US Preventive Services Task Force recently changed its guidance to say that "the 


\begin{tabular}{|c|c|}
\hline Organisation, last published update & Recommendation \\
\hline US Preventive Services Task Force, 2018 & $\begin{array}{l}\text { Provide information about potential benefits and harms of screening for men aged 55-69 years } \\
\text { Recommend against screening for men aged } \geq 70 \text { years }\end{array}$ \\
\hline $\begin{array}{l}\text { Canadian Task Force on Preventive Health } \\
\text { Care, } 2014\end{array}$ & $\begin{array}{l}\text { Recommend against routine screening } \\
\text {-Weak recommendation in men aged 55-69, and strong in other ages }\end{array}$ \\
\hline American Cancer Society, 2016 & $\begin{array}{l}\text { Provide information about uncertainties, risks, and potential benefits of screening to enable informed } \\
\text { decision making } \\
\text { Recommend screening discussions for: } \\
\text { - Men aged } 50 \text { years who are at average risk (expected to live at least } 10 \text { more years) } \\
\text { - Men aged } 45 \text { years who are at high risk (African-Americans, and men with a first degree relative with } \\
\text { prostate cancer diagnosed at }<65 \text { years old) } \\
\text { - Men aged } 40 \text { years who are at very high risk (more than one first degree relative with prostate cancer } \\
\text { diagnosed at }<65 \text { years old) }\end{array}$ \\
\hline $\begin{array}{l}\text { American Academy of Family Physicians, } \\
2012\end{array}$ & $\begin{array}{l}\text { Adopted the US Preventive Services Task Force } 2012 \text { recommendation, which recommended against } \\
\text { screening }\end{array}$ \\
\hline American Urological Association, 2015 & $\begin{array}{l}\text { Shared decision making for men aged 55-69 years } \\
\text { Recommend against routine screening in men aged }<40 \text { years or those with life expectancy }<10-15 \text { years }\end{array}$ \\
\hline American College of Physicians, 2015 & $\begin{array}{l}\text { Shared decision making for men aged 50-69 years } \\
\text { Recommend against screening in men aged }<50 \text { or } \geq 70 \text { years, those with life expectancy }<10 \text { years, and those } \\
\text { who had not had informed discussion }\end{array}$ \\
\hline $\begin{array}{l}\text { US National Comprehensive Cancer Network, } \\
2018\end{array}$ & $\begin{array}{l}\text { Offer screening to men aged } 45-75 \text { years. Begin discussing PSA screening with African-American men several } \\
\text { years earlier than white men. Continue screening beyond } 75 \text { years old with caution in healthy patients with } \\
\text { little or no comorbidity }\end{array}$ \\
\hline European Association of Urology, 2018 & $\begin{array}{l}\text { Recommend against PSA testing without prior counselling on potential risks and benefits } \\
\text { Offer an individualised, risk-adapted strategy for early detection to well informed men with good performance } \\
\text { status and life expectancy } \geq 10-15 \text { years } \\
\text { Recommend screening for men aged }>50 \text { years, or }>45 \text { years for men with positive family history or African- } \\
\text { American ethnicity. } \\
\text { Recommend against routine screening for men with life expectancy }<15 \text { years }\end{array}$ \\
\hline European Society for Medical Oncology, 2015 & Recommend against population based screening \\
\hline UK National Screening Committee, 2016 & Recommend against systematic population screening \\
\hline
\end{tabular}

decision about whether to be screened for prostate cancer should be an individual one," without clearly suggesting for or against screening ${ }^{9}$ : previously it recommended against screening in that group. National Cancer Center Network (NCCN) guidelines (which represents cancer centres in the USA) recommends initiating PSA screening at age 45 years. ${ }^{10}$ Guidelines from the American Urological Association (AUA) ${ }^{11}$ and European Association of Urology (EAU) ${ }^{12}$ recommend a discussion about PSA screening with patients.

\section{Uptake of PSA testing}

The incidence of prostate cancer has dramatically increased over the last quarter century. This has been associated with widespread use of prostate specific antigen (PSA) testing detecting early stage prostate cancers. ${ }^{13}$ There is wide variation in the adoption of prostate cancer screening. In the UK, about 39\% of men aged 45-69 years have undergone PSA testing in the past 10 years. ${ }^{14}$ In Sweden 23\% of men aged 50-69 had a PSA test in the previous 12 months and $58 \%$ in the previous 10 years. ${ }^{15}$ Although the rates of screening have declined during the past decade in the US, ${ }^{16-18}$ up to half of US men aged 60-74 undergo screening each year. Also, as many as 33\% of elderly US men with competing medical comorbidities at high risk of dying from other cause underwent screening, and twice as many of these men recalled discussing the potential benefits rather than harms of screening. ${ }^{19}$ African-Americans were less likely to have been screened than non-African US men. ${ }^{20}$ Overall, two thirds of men reported no past discussion with physicians about the advantages, disadvantages, or scientific uncertainty and no shared decision making about prostate cancer screening. ${ }^{20}$

\section{The evidence}

The updated systematic review on the benefits and harms of PSA screening pools data from five randomised controlled trials (with ERSPC comprising eight European countries), which enrolled a total of 721718 men (with 419582 included in the latest CAP trial). ${ }^{1}$

\section{Main characteristics and limitations of the trials}

Figure 2 provides an overview of the trials' characteristics and the patients included. All trials had methodological limitations. In the CAP trial only $36 \%$ of men randomised to the screening arm actually underwent PSA testing (that is, low adherence to screening), while about $10-15 \%$ in the non-screening arm were actually tested (that is, contamination). CAP also differed from other large scale trials in that it used one-time screening, whereas others used repeated screening with intervals varying from annual to every two years or more.

The Prostate, Lung, Colorectal and Ovarian (PLCO) Cancer Screening trial conducted in the US ${ }^{21}$ lacked allocation concealment, and rates of PSA testing in the nonscreening arm exceeded $50 \%$, possibly as high as $80 \%{ }^{22}$

The European Randomised Study of Screening for Prostate Cancer (ERSPC) was conducted in eight European countries. ${ }^{5}$ There was possibly inadequate allocation concealment, and there are concerns that groups may have received different quality of treatment for prostate cancer (performance bias). Nevertheless, the systematic review authors judged the ERSPC trial to be the one that was probably least affected by bias. Based on a predefined sensitivity analysis, ${ }^{1}$ the $B M J$ Rapid Recommendations panel decided to appraise both the summary of the whole 


\section{DATA SOURCES Use this information to gauge how similar your patients' conditions are} to those of people studied in the trials

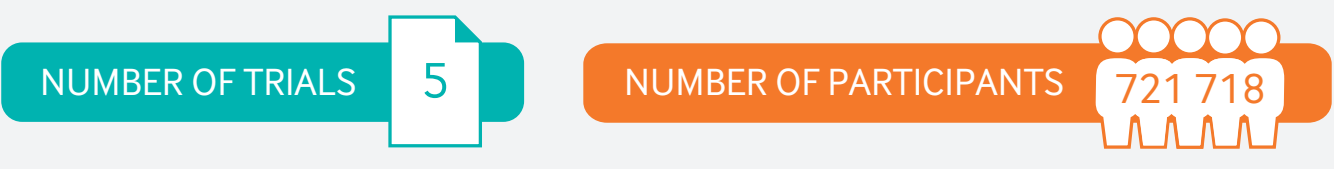

\section{TRIAL CHARACTERISTICS}

\begin{tabular}{|c|c|}
\hline \multicolumn{2}{|l|}{ Screening frequency } \\
\hline $\begin{array}{l}\text { One-time PSA } \\
\text { screening }\end{array}$ & 2 . $\begin{array}{l}00000 \\
436306 \\
\text { ㄴnn }\end{array}$ \\
\hline Annual PSA screening & 2 .00000 \\
\hline $\begin{array}{l}\text { PSA screening at least } \\
\text { every } 2-4 \text { years }\end{array}$ & 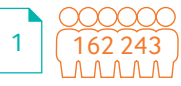 \\
\hline \multicolumn{2}{|c|}{$\begin{array}{l}\text { Digital rectal examination (DRE) } \\
\text { performed in addition to PSA }\end{array}$} \\
\hline DRE and PSA screening & 3 Oo0000 \\
\hline PSA only screening & $\begin{array}{l}000000 \\
271068 \\
57101 \\
\text { ñn }\end{array}$ \\
\hline \multicolumn{2}{|l|}{ Follow-up duration } \\
\hline $\begin{array}{l}\text { Reported } 10 \text { year } \\
\text { follow up }\end{array}$ & 1 . $\begin{array}{l}00000 \\
408825 \\
\text { ㄴํㄴ }\end{array}$ \\
\hline $\begin{array}{l}\text { Reported } 11 \text { year } \\
\text { follow up }\end{array}$ & 1 .00000 \\
\hline $\begin{array}{l}\text { Reported } 13 \text { year } \\
\text { follow up }\end{array}$ & 1 . 100000 \\
\hline $\begin{array}{l}\text { Reported } 15 \text { year } \\
\text { follow up }\end{array}$ & 1 \\
\hline $\begin{array}{l}\text { Reported } 20 \text { year } \\
\text { follow up }\end{array}$ & 1 O00000 \\
\hline
\end{tabular}

\section{PARTICIPANT CHARACTERISTICS}

NUMBER OF PATIENTS ENROLLED

Thousands

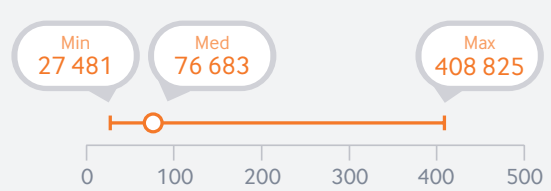

\section{MEAN AGE $\dagger$}

at baseline

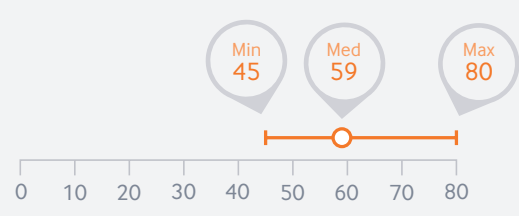

ADHERENCE

Proportion of participants in the screening arm who actually underwent PSA testing

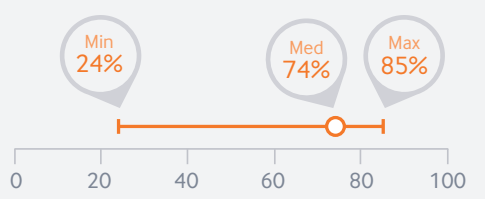

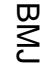

产

MEN WITH

FAMILY

HISTORY

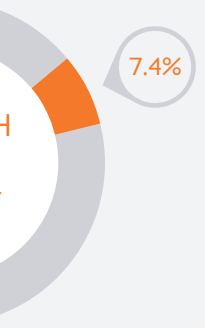

Distribution reported in only 2 studies

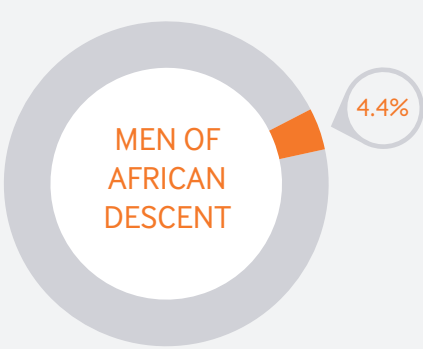

Distribution reported in only 1 study

\section{CONTAMINATION $\ddagger$}

Proportion of participants in the non-screening arm who actually underwent PSA testing

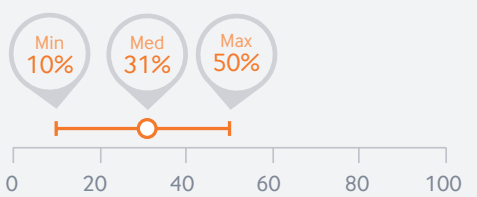

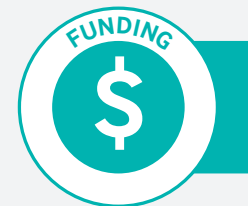

4 trials reported non-industry funding

1 trial reported limited industry funding*

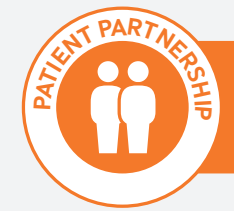

No patient involvement

reported in trial designs

* Swedish arm of ERSPC trials received funding from Abbott Pharmaceuticals

† Age distribution reported in only 2 studies

‡ Estimated, not directly measured in all except one study

Fig 2 Characteristics of patients and trials included in systematic review of the use of the prostate-specific antigen (PSA) test for prostate cancer screening. ${ }^{1}$ 
body of evidence as well as selected data at lower risk of bias from the ERSPC study (see main infographic).

Although most studies reported mortality and cancer incidence, there was limited randomised data on complications from biopsies or subsequent prostate cancer treatment and on quality of life. The systematic review team therefore searched for available follow-up evidence from the intervention arms of included trials and followup publications.

They used ERSPC sub-data for quality of life (that is, the Finnish arm of the study $)^{23}$ and false positive rates. ${ }^{24}$ They estimated false negative rates among men with a low PSA level from a follow-up cohort study of the Prostate Cancer Prevention Trial. ${ }^{25}$ Complications rates from subsequent treatment modalities were obtained from the ProtecT trial embedded in the CAP trial-in which patients diagnosed with prostate cancer in the CAP screening trial were randomised to active monitoring, radical prostatectomy, or radical radiotherapy with hormones. ${ }^{26}$ Similarly, complication rates from biopsies were obtained from the Prostate Biopsy Effects cohort study nested within the ProtecT trial. ${ }^{27}$ By modelling the likelihood of elevated PSA values, biopsies, cancer diagnoses, and treatment modalities (from the NIH's Surveillance, Epidemiology, and End Results (SEER) programme), ${ }^{28}$ the linked systematic review estimated the absolute number of biopsy and treatment related complications among men who underwent screening versus those who did not (see infographic and appendix $3 \mathrm{on}$ bmj.com for more details). The quality of evidence assessment with GRADE considers the unique limitations in the evidence for each outcome.

\section{Evidence on men's values and preferences}

Evidence suggests that different men judge the benefits and harms of PSA testing and its consequences differently. The linked systematic review on the values and preferences of men considering PSA screening ${ }^{29}$ included studies that reported quantitative data on the degree of benefits (such as reduction in mortality risk) that men would require and degree of harms (such as increase in risk of incontinence) that men would be willing to accept to undergo prostate cancer screening. Five studies were identified that investigated a direct choice related to PSA screening. ${ }^{29}$

The studies used different methodologies and varied considerably in how their outcomes were reported. One study showed that men were willing to forego screening with a benefit of $2 \%$ on prostate cancer mortality if it increases their probability of avoiding unnecessary biopsies by $10 \%$ or avoiding unnecessary treatment by $10 \% .^{30}$ In another study, men were willing to accept between 65 and 233 per 10000 unnecessary biopsies to avoid one per 10000 prostate cancer deaths. These results varied with age: men in their 50s were willing to accept more unnecessary biopsies than men in their 40 s or in their $60 \mathrm{~s}^{31}$

The review also included six studies in which men were presented with decision aids showing outcomes such as prostate cancer diagnosis and prostate cancer mortality. Willingness to undergo screening varied from $37 \%$ in a study displaying a reduction in mortality of 10 per 1000 men to $44 \%$ in a study displaying a reduction in mortality of 7 per $1000 .{ }^{29}$ The review found no studies that specifically investigated whether the men's values and preferences differed among men with a family history of prostate cancer, men of African descent, or men of lower socioeconomic class.

\section{Understanding the recommendation}

The recommendation against PSA screening is weak because of the small and uncertain benefits of screening on prostate cancer mortality and the large variability in men's values and preferences. In practice, a weak recommendation means that shared decision making is important. Clinicians should support men considering screening to make a well informed decision in line with their own risk profile and individual values and preferences. Another implication of our weak recommendation is that clinicians do not need to raise the issue systematically with their patients. They could raise PSA screening or wait for the patient to raise the issue. Both approaches are reasonable. It depends on the patient's context and competing issues in each clinical encounter.

The panel believes that most informed men considering screening would decline it, although some would choose to undergo screening, accepting the diagnostic and therapeutic burden and harms that can result.

\section{Absolute benefits and harms}

The main infographic explains the recommendation and provides an overview of the absolute benefits and harms of screening at a 10 year time horizon for consistency and easier communication. However, the individual trials varied in their duration of follow-up from 10 to 20 years (fig 2), and we used the relative estimates of effect, pooled in the linked systematic review, at the longest available follow-up time. ${ }^{1}$ For the 10 year time horizon, we used as baseline risk in the non-screening arm of the CAP trial. It provided the most contemporary estimates of risks from a large sample of men representative of a general practice setting. ${ }^{2}$

\section{Death and cancer diagnosis}

PSA screening may increase the detection of prostate cancer (7 more per 1000 men (95\% confidence interval 1 to 15 more) at 10 years), particularly of localised cancer ( 7 more per 1000 men ( 2 to 15 more)). But the data show no difference in prostate cancer mortality. Overall confidence in these estimates across these outcomes was low because of risk of bias as well as the inconsistency of findings across studies.

When focusing on studies at lower risk of bias-ERSPC trials-the panel was confident that over a 10 year period:

- PSA screening probably has little or no effect on death

- All-cause mortality (0 fewer per 1000 men (95\% CI 3 fewer to 3 more))

- Prostate cancer mortality (1 fewer per 1000 (1 to 0 fewer))

- Prostate cancer mortality is similar at longer periods of up to 18 years of follow-up (1 to 2 fewer per 1000 men $)^{1}$ 
- PSA screening probably increases diagnosis of prostate cancer

- Detection of any prostate cancer (18 more per 1000 men (16 to 20 more))

- Detection of localised cancer (14 more per 1000 (13 to 16 more))

- But it probably results in a small decrease in detection advanced prostate cancer (3 fewer per 1000 (4 to 2 fewer)).

The panel was also confident that:

- About two thirds of men offered a biopsy because of an elevated PSA result will have normal biopsy results and no prostate cancer (that is, false positive results of PSA screening)

- About $15 \%$ of men with a normal PSA result will subsequently be diagnosed with prostate cancer; with about $2 \%$ of men with a normal PSA result diagnosed with advanced cancer (that is, false negative results of PSA screening)

- Each biopsy bears a substantial risk of side effects and serious complications, including blood in semen $(93 \%)$, blood in urine $(66 \%)$, pain $(44 \%)$, fever (18\%), and admission to hospital for sepsis (1-2\%).

Thus, considering that about one in seven men who undergo PSA screening will have an elevated PSA result $\mathrm{t}^{25}$ and most of them will undergo biopsy (about $85 \%$ in the CAP and ERSPC trials, see appendix 3 on bmj.com):

- Among a hypothetical population of 1000 men, about 94 more will present with blood in the semen with PSA screening, 67 more with blood in the urine, 45 more with pain, 19 more with fever, and 1 more hospitalised for sepsis, due to a prostate biopsy

- The panel acknowledges uncertainty in these projected estimates, as they were based on modelling and several assumptions in the rates of biopsies and cancers detected in men that were screened and in those who were not. These are likely to vary across clinical contexts and diagnostic strategies. For example, new approaches (including genetic or biomarkers, risk stratification tools, and MRI-guided biopsy ${ }^{32-34}$ ) have the potential for avoiding biopsies in men with non-progressive and slowly progressive cancer, and thus diminish the likelihood of harm from their complications when entering screening through PSA testing. However, the impact of such modalities on patient-important outcomes remains uncertain.

\section{Harms linked to management of prostate cancer}

The panel was confident in the complications rates reported for treatments of prostate cancer, in particular:

- Urinary incontinence (pad use at 6 years after treatment) was present in $17 \%$ of men who had surgery, $4 \%$ who had radiotherapy, and $8 \%$ of men under active surveillance

- Erections not firm enough for intercourse were present in $83 \%$ of men who had surgery, $73 \%$ who had radiotherapy, and $70 \%$ under active surveillance.
Thus,

- Applying these numbers to a hypothetical 1000 men, ${ }^{28}$ about three more will present with urinary incontinence (any pad use) and 25 more will have an erection not firm enough for intercourse due to treatment for prostate cancer diagnosed through PSA screening (see appendix 3). Once again, the panel has low confidence in these projected estimates, as they are based on several assumptions depending on the particular context and required data modelling. New diagnostic strategies could also shift the proportions of men who enter active surveillance rather than radical surgery or radiotherapy.

\section{Quality of life}

The panel was less confident about the impact of screening on the overall quality of life or the anxiety of having cancer:

- There was no difference in quality of life between men who undergo PSA screening and those who do not. But this comparison was available only in a subset of men from one of the trials $(\mathrm{n}=1088$, more details through the MAGICapp within the main infographic). ${ }^{23}$

- There is no randomised evidence comparing PSA screening with non-screening in regard to the anxiety related to a cancer diagnosis. A large cohort study in Sweden among 4.3 million men showed an increased risk of suicide (relative risk 2.6 (95\% CI 2.1 to 3.0)) and cardiovascular events (1.3 (1.3 to 1.3)) during the first year after diagnosis..$^{35}$ A US cohort study with 343000 men showed no increased risk of suicide during the first year after the widespread use of PSA screening (after 1993) but an increased risk of cardiovascular death during the first month after diagnosis (adjusted relative risk 1.55 (1.3 to 1.8)). ${ }^{36}$ Thus it remains uncertain whether screening results in changes in anxiety about cancer.

\section{Adapting the offer for men at higher risk of prostate cancer and death}

The linked systematic review did not find a relative subgroup effect by age: the effects of screening are consistent across age strata. ${ }^{1}$ Age of men enrolling in the studies ranged from 45 to 80 years, with most aged 50-69 years. The panel believes the evidence thus applies to men regardless of age. However, any possible benefit of screening is likely to become negligible as life expectancy decreases due to age or comorbidities.

There were no randomised data on whether screening efficacy differed in those with a family history of prostate cancer, men of African descent, or men from lower socioeconomic levels. It remains uncertain whether the relative effect of screening is similar to that in the general population. However, these factors are associated with higher incidence of prostate cancer and higher risk of prostate cancer death in observational studies, as well as in follow-up publications of the trials included in the linked review (Finnish ${ }^{3738}$ and Swiss ${ }^{39}$ arms from the 
ERSPC trial and the PLCO trial $\left.{ }^{40}\right)$. Using evidence from these trials, we adapted the baseline risk in our summary of findings, using the same studies at lower risk of bias (that is, ERSPC data). In these studies, family history was assessed by self reporting in a questionnaire and defined positive if a man reported that his father or at least one brother had been diagnosed with prostate cancer. ${ }^{3739}$ For race or ethnicity, non-Hispanic black men were compared with non-Hispanic white men. ${ }^{40}$ Level of education was used as a proxy for socioeconomic status, and men with primary education only were defined as having a low level of education and men with secondary or tertiary education defined as having high level of education. ${ }^{38}$

For men of African descent, over a 10 year period:

- The baseline risk of developing prostate cancer of any stage is likely higher than that of the general population (estimated at about 51 per 1000 men diagnosed), and PSA screening probably increases their detection of any stage cancer by a larger magnitude than in the general population (29 more per 1000 men (95\% CI 26 to 32 more))

- Baseline risk of prostate cancer mortality is likely also higher than in the general population of men considering screening (estimated at about 7 per 1000 men dying at 10 years). However, PSA screening had a similar small effect in reducing prostate cancer mortality in absolute terms (1 fewer per 1000 ( 2 to 1 fewer)).

For men with family history, over a 10 year period:

- As for men with African descent, the baseline risk of developing prostate cancer is likely higher than in the general population (estimated at about 50 per 1000 men diagnosed with any stage prostate cancer; and about 25 per 1000 are localised cancers). PSA screening probably increases their detection of any stage cancer (29 more per 1000 (26 to 31 more)) as well as localised cancers (19 more per 1000 (17 to 21 more))

- These baseline risk estimates are based on studies that defined family history as positive if a man reported that his father or at least one brother had been diagnosed with prostate cancer. These baseline risk estimates may increase with increasing number of relatives diagnosed with prostate cancer. $^{41}$

For men with lower level of education, over a 10 year period:

- There was limited data on how much more these men were at higher baseline risk. Using lower level of education as a proxy of lower socioeconomic status, ${ }^{38}$ we estimated that baseline risk of prostate cancer mortality was higher (about 4 per 1000 men dying at 10 years) as well as all-cause mortality (about 196 per 1000 men)

- The absolute effect of PSA screening is overall comparable to that in the other subgroups, with a small reduction in prostate cancer mortality (about 1 fewer per 1000 men (1 to 0 fewer))

- PSA screening probably has little or no effect on all-cause mortality (about 4 fewer per 1000 (10 to 0 fewer)).

\section{Values and preferences}

The panel, including the patient partners, felt that this variability in values and preferences contributes to a weak recommendation. The recommendation against screening reflects a belief that most men would value avoiding complications from biopsies and subsequent treatment because the reduction in prostate cancer and death from screening is small and uncertain. Prostate cancer will often, though not always, remain indolent.

Men who place a high value on avoiding complications from biopsies and subsequent treatment are likely to decline screening. In contrast, men who place a higher value on even a small reduction of prostate cancer may opt for screening. Several panel members felt that higher risk patients-such as patients with family history of cancer or of African descent-may be more likely to seek screening because they may worry more about prostate cancer and want to rule out the diagnosis.

For men considering screening, shared decision making is critical to ensure that their decision is in line with their own values and preferences. The evidence summarised in this Rapid Recommendation is available in MAGICapp as decision aids that can support shared decision making (https://app.magicapp.org/public/guideline/n32gkL).

\section{Practical issues and other considerations}

Figure 3 outlines the key practical issues. PSA testing can be performed on any normal blood sample, but prostate biopsies and their follow-up have important implications for daily life.

Lower urinary tract symptoms (slow urine stream, sensation of incomplete emptying, increased urinary frequency) are common complaints in adult men that can have a major impact on quality of life. Benign prostatic enlargement is the major cause. Evidence to date indicates that men with these complaints are not at increased risk of prostate cancer.

For men who chose to undergo PSA testing, the optimal frequency of screening remains unknown. Figure 2 summarises the frequency used in the different trials, yet the accompanying systematic review did not find any significant subgroup effect of the effect of screening based on these different frequencies. ${ }^{1}$ Given that the ERSPC data are likely at lower risk of bias, PSA screening every four years-rather than, say, every year or only once in a lifetime-may be the optimal interval.

\section{Costs and resources}

Results from a recent cost-effectiveness study modelled for the US suggested that screening between the ages of 55 and 69 years combined with active surveillance for low risk men could only be cost-effective at a $\$ 100000$ threshold if the screening frequency remains low (every four years) and active surveillance is offered to all men with low risk prostate cancer (that is, Gleason score $\leq 6$ and stage $\leq \mathrm{T} 2 \mathrm{a}$ ). Strategies with shorter screening intervals or in which immediate treatment is offered to all men were not cost-effective. ${ }^{42}$ Although the Rapid Recommendations panel focused on the patients' priorities rather than those of society, our recommendation is compatible with these findings. 


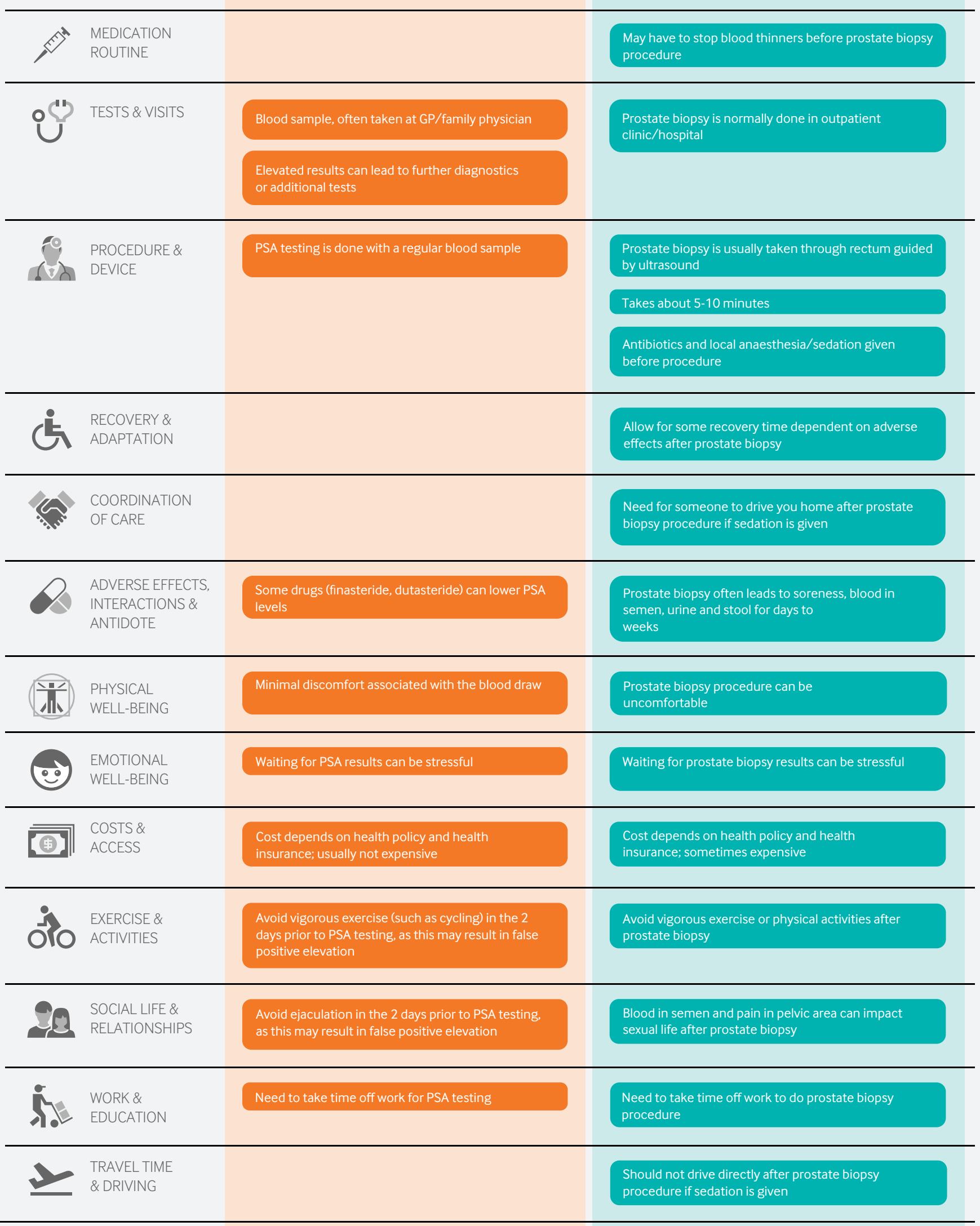




\section{EDUCATION INTO PRACTICE}

- To whom do you consider offering PSA screening for prostate cancer? Is this article likely to change your practice?

- How do you explain potential benefits and harms from PSA screening to men in your consultation? How can this article help you discuss these outcomes?

- How can you support patients to make a decision about PSA screening according to their values and preferences?

\section{Uncertainties for future research}

Recent evidence suggests that incorporating MRI in the investigation of those with a positive PSA test result decreases the false positive rate, and thus the number of patients undergoing unnecessary biopsies, and may also increase the accuracy of biopsies in those who do have prostate cancer. The Rapid Recommendations panel considered addressing this issue in the guideline, but the impact of MRI on long term outcomes of prostate cancer incidence, mortality, and complications of treatment remains uncertain. Sophisticated decision modelling might shed light on this issue, but the panel decided not to conduct such an analysis because of logistic and feasibility considerations, and because the panel's review of the evidence suggests that modelling would introduce further uncertainties regarding the impact of MRI on patient-important outcomes.

Key research question to inform decision makers and future guidelines include

- Could new screening and diagnostic techniques reduce the harms and burden of the diagnostic procedure by better identifying non-progressive and slowly progressive cancer from cancer that is likely to become symptomatic and affect quality or length of life? These strategies may include genetic markers or biomarkers, risk stratification tools, or MRI guided biopsy. ${ }^{32}$ For example, two recent high quality studies on MRI guided biopsy have shown encouraging results of MRI to reduce overdiagnosis, ${ }^{334} \mathrm{but}$ the impact of this strategy on long term, patientimportant outcomes (such as prostate cancer incidence, mortality, and complications of treatment) remains uncertain.

- For men opting for screening, what would be the ideal age range and screening interval? Randomised trials varied in their offer of a one-off or repeated PSA testing and it remains uncertain which strategy is more suitable.

- What is the impact of screening on men at higher baseline risk (men with a family history of cancer, of African descent, and of lower socioeconomic status)? Are their values and preferences different from those of men in the general population?

\section{Updates to this article}

The final table shows evidence that has emerged since the publication of this article. As new evidence is published,

\begin{tabular}{l}
\hline $\begin{array}{l}\text { New evidence which has emerged after initial publication } \\
\text { New }\end{array} \quad \begin{array}{l}\text { Implications for } \\
\text { Date evidence Citation } \quad \text { Findings } \\
\text { recommendation(s) }\end{array}$ \\
There are currently no updates to the article. \\
\hline
\end{tabular}

\section{HOW PATIENTS WERE INVOLVED IN THE CREATION}

\section{OF THIS ARTICLE:}

Three men eligible for PSA screening were full panel members. They identified important outcomes and led the discussion on values and preferences. They fully participated in the teleconferences and email discussions on the evidence and the recommendation. They also contributed to the identification of practical issues related to the decision to undergo PSA screening, and met all authorship criteria for the present article.

a group will assess the new evidence and make a judgment on the extent it is expected to alter the recommendation.

We thank Drs Tuomas Kilpeläinen and Eric Miller for providing additional information about the original studies.

Competing interests: All authors have completed the BMJ Rapid Recommendations interests disclosure form, and a detailed description of all disclosures is reported in appendix 1 . As with all BMJ Rapid Recommendations, the executive team and The BMJ judged that no panel member had any financial conflict of interest. Professional and academic interests are minimised as much as possible, while maintaining necessary expertise on the panel to make fully informed decisions.

\section{Funding: This guideline was not funded.}

Transparency: KAO Tikkinen and T Agoritsas affirm that the manuscript is an honest, accurate, and transparent account of the recommendation being reported; that no important aspects of the recommendation have been omitted; and that any discrepancies from the recommendation as planned (and, if relevant, registered) have been explained.

1 Ilic D, Djulbegovic M, Jung JH, et al. Prostate cancer screening with prostate-specific antigen (PSA) test: a systematic review and metaanalysis. BM/ 2018;362:k3519. 10.1136/bmj.k3519.

2 Martin RM, Donovan JL, Turner EL, et al. CAP Trial Group. Effect of a lowintensity PSA-based screening intervention on prostate cancer mortality: The CAP Randomized Clinical Trial. JAMA 2018;319:883-95. 10.1001/ jama.2018.0154 pmid:29509864.

3 Global Burden of Disease Cancer Collaboration. The Global burden of cancer 2013. JAMA Oncol 2015:1:505-27. 10.1001/ jamaoncol.2015.0735. pmid:26181261.

4 Østerø I Jákupsstovu J, Brodersen J. Do men with lower urinary tract symptoms have an increased risk of advanced prostate cancer?BM 2018;361:k1202. 10.1136/bmj.k1202. pmid:29724877.

5 Schröder FH, Hugosson J, Roobol MJ, et al. ERSPC Investigators. Screening and prostate cancer mortality: results of the European Randomised Study of Screening for Prostate Cancer (ERSPC) at 13 years of follow-up. Lancet 2014;384:2027-35. 10.1016/S01406736(14)60525-0. pmid:25108889.

6 Loeb S, Catalona WJ. Prostate-specific antigen screening: pro. Curr Opin Urol 2010;20:185-8, 10.1097/

MOU.0b013e3283384047. pmid:20224413.

7 Ilic D, Neuberger MM, Djulbegovic M, Dahm P. Screening for prostate cancer. Cochrane Database Syst Rev 2013;(1):CD004720. 10.1002/14651858.CD004720.pub3. pmid:23440794.

8 Bell N, Connor Gorber S, Shane A, et al. Canadian Task Force on Preventive Health Care. Recommendations on screening for prostate cancer with the prostate-specific antigen test. CMAJ 2014;186:1225-34 10.1503/cmaj.140703. pmid:25349003.

9 Grossman DC, Curry SJ, Owens DK, et al. US Preventive Services Task Force. Screening for prostate cancer: Us preventive services task force recommendation statement. JAMA 2018:319:1901-13.10.1001/ jama.2018.3710. pmid:29801017.

10 Carroll PR, Parsons JK, Andriole G, et al. National comprehensive cancer network. Prostate cancer early detection, version 1.2014. Featured updates to the NCCN Guidelines. / Nat Compr Canc Netw 2014:12:1211-9, quiz 1219. 10.6004/ jnccn.2014.0120 pmid:25190691.

11 Carter HB, Albertsen PC, Barry MJ, et al. Early detection of prostate cancer: AUA Guideline. J Urol 2013;190:419-26. 10.1016/j. juro.2013.04.119. pmid:23659877.

12 European Association of Urology. Mottet N, Bellmunt I Briers E et al. EAU - ESTRO - ESUR - SIOG Guidelines on prostate cancer. 2018. https:// uroweb.org/guideline/prostate-cancer/.

13 Global Burden of Disease Cancer Collaboration. Global, regional, and national cancer incidence, mortality, years of life lost, years lived with disability, and disability-adjusted life-years for 32 cancer groups, 1990 to 2015: a systematic analysis for the Global Burden of Disease Study. JAMA Oncol 2017;3:524-48. 10.1001/ jamaoncol.2016.5688. pmid:27918777. 
14 Young GJ, Harrison S, Turner EL, et al. Prostate-specific antigen (PSA) testing of men in UK general practice: a 10-year longitudinal cohort study. BMJ Open 2017;7:e017729.10.1136/ bmjopen-2017-017729. pmid:29084797.

15 Nordström T, Bratt O, Örtegren J, Aly M, Adolfsson J, Grönberg H. A population-based study on the association between educational length, prostate-specific antigen testing and use of prostate biopsies. Scand J Urol 2016;50:104-9. 10.3109/21681805.2015.1113200. pmid:26625178.

16 Jemal A, Fedewa SA, Ma J, et al. Prostate cancer incidence and PSA testing patterns in relation to USPSTF screening recommendations. |AMA 2015;314:2054-61.10.1001/ jama.2015.14905. pmid:26575061.

17 Drazer MW, Huo D, Eggener SE. National prostate cancer screening rates after the 2012 US Preventive Services Task Force recommendation discouraging prostate-specific antigen-based screening. J Clin Oncol 2015;33:2416-23.10.1200/ JCO.2015.61.6532. pmid:26056181.

18 Van der Meer S, Kollen B], Hirdes WH, et al. Impact of the European Randomized Study of Screening for Prostate Cancer (ERSPC) on prostate-specific antigen (PSA) testing by Dutch general practitioners BJU Int 2013;112:26-31. 10.1111/bju.12029. pmid:23465178.

19 Drazer MW, Prasad SM, Huo D, et al. National trends in prostate cancer screening among older American men with limited 9-year life expectancies: evidence of an increased need for shared decision making. Cancer 2014;120:1491-8. 10.1002/cncr.28600. pmid:24523016.

20 Misra-Hebert AD, Hu B, Klein EA, et al. Prostate cancer screening practices in a large, integrated health system: 2007-2014. BJU Int 2017:120:25764. 10.1111/bju.13793. pmid:28139034

21 Andriole GL, Crawford ED, Grubb RL 3rd, et al. PLCO Project Team. Prostate cancer screening in the randomized Prostate, Lung, Colorectal, and Ovarian Cancer Screening Trial: mortality results after 13 years of follow-up. / Natl Cancer Inst 2012;104:125-32. 10.1093/inci/ djr500 pmid:22228146.

22 Pinsky PF, Prorok PC, Yu K, et al. Extended mortality results for prostate cancer screening in the PLCO trial with median follow-up of 15 years. Cancer 2017;123:592-9.10.1002/cncr.30474. pmid:27911486.

23 Booth N, Rissanen P, Tammela TL, Määttänen L, Taari K, Auvinen A. Health-related quality of life in the Finnish trial of screening for prostate cancer. Eur Urol 2014:65:39-47.10:1016/j. eururo.2012.11.041. pmid:23265387.

24 Kilpeläinen TP, Tammela TL, Roobol M, et al. False-positive screening results in the European randomized study of screening for prostate cancer. Eur J Cancer 2011;47:2698-705. 10.1016/i. ejca.2011.06.055 pmid.21788129.

25 Thompson IM, Pauler DK, Goodman PJ, et al. Prevalence of prostate cancer among men with a prostate-specific antigen level $<$ or $=4.0$ ng per milliliter. N EnglJ Med 2004;350:2239-46. 10.1056/ NEJMoa031918. pmid:15163773.

26 Donovan JL, Hamdy FC, Lane JA et al. ProtecT Study Group*. Patientreported outcomes after monitoring, surgery, or radiotherapy for prostate cancer. N Engl J Med 2016;375:1425-37. 10.1056/ NEJMoa1606221. pmid:27626365.

27 Rosario DJ, Lane JA, Metcalfe C, et al. Short term outcomes of prostate biopsy in men tested for cancer by prostate specific antigen: prospective evaluation within ProtecT study. BMJ 2012;344:d7894. 10.1136/bmj. d7894. pmid:22232535.

28 Miller KD, Siegel RL, Lin CC, et al. Cancer treatment and survivorship statistics, 2016. CA Cancer J Clin 2016;66:271-89.10.3322/ caac.21349. pmid:27253694

29 Vernooii RWM, Lytvyn L, Pardo-Hernandez H, et alValues and preferences of men for undergoing prostate-specific antigen screening for prostate cancer: a systematic review. BMJ Open 2018;0:e025470. 10.1136/ bmjopen-2018-025470

30 de Bekker-Grob EW, Rose JM, Donkers B, Essink-Bot ML, Bangma CH, Steyerberg EW. Men's preferences for prostate cancer screening: a discrete choice experiment. Br / Cancer 2013;108:533-41.10.1038/ bjc.2013.5. pmid:23361056

31 Howard K, Salkeld GP, Patel MI, Mann GJ, Pignone MP. Men's preferences and trade-offs for prostate cancer screening: a discrete choice experiment. Health Expect 2015;18:3123-35. 10.1111/ hex.12301. pmid:25382490.

32 Dahm P. Future of screening for prostate cancer. BMJ 2017;358:j4200. 10.1136/bmj.j4200. pmid:28928226

33 Ahmed HU, El-Shater Bosaily A, Brown LC, et al. PROMIS study group. Diagnostic accuracy of multi-parametric MRI and TRUS biopsy in prostate cancer (PROMIS): a paired validating confirmatory study. Lancet 2017:389:815-22 10.1016/S0140-6736(16)324011. pmid: 28110982

34 Kasivisvanathan V, Rannikko AS, Borghi M, et al. PRECISION Study Group Collaborators. MRI-targeted or standard biopsy for prostatecancer diagnosis. N Engl J Med 2018;378:1767-77. 10.1056/ NEIMoa1801993. pmid:29552975.

35 Fall K, Fang F, Mucci LA, et al. Immediate risk for cardiovascular events and suicide following a prostate cancer diagnosis: prospective cohort study. PLoS Med 2009;6:e1000197. 10.1371/journal. pmed.1000197. pmid:20016838.
36 Fang F, Keating NL, Mucci LA, et al. Immediate risk of suicide and cardiovascular death after a prostate cancer diagnosis: cohort study in the United States. / Natl Cancer Inst 2010:102:307-14 10.1093/inci/ djp537. pmid:20124521.

37 Saarimäki L, Tammela TL, Määttänen L, et al. Family history in the Finnish Prostate Cancer Screening Trial. Int J Cancer 2015;136:2172-7. 10.1002/ijc.29243. pmid:25274038.

38 Kilpeläinen TP, Talala K, Raitanen J, et al. Prostate cancer and socioeconomic status in the Finnish Randomized Study of Screening for Prostate Cancer. Am J Epidemiol 2016;184:720-31. 10.1093/aje/ kww084. pmid:27777219.

39 Randazzo M, Müller A, Carlsson S, et al. A positive family history as a risk factor for prostate cancer in a population-based study with organised prostate-specific antigen screening: results of the Swiss European Randomised Study of Screening for Prostate Cancer (ERSPC, Aarau). BJU Int 2016;117:576-83.10.1111/bju.13310. pmid:26332304

40 Miller EA, Pinsky PF, Black A, Andriole GL, Pierre-Victor D. Secondary prostate cancer screening outcomes by race in the Prostate, Lung, Colorectal, and Ovarian (PLCO) Screening Trial. Prostate 2018;78:830-8. 10.1002/pros.23540. pmid:29667217.

41 Bratt O, Drevin L, Akre O, Garmo H, Stattin P. Family history and probability of prostate cancer, differentiated by risk category: a nationwide population-based study. J Natl Cancer Inst 2016;108:djw110. 10.1093/ jnci/djw110. pmid: 27400876

42 de Carvalho TM, Heijnsdijk EAM, de Koning HI. Comparative effectiveness of prostate cancer screening between the ages of 55 and 69 years followed by active surveillance. Cancer 2018;124:507-13. 10.1002/ cncr.31141. pmid:29231973.

43 Siemieniuk RA, Agoritsas T, Macdonald H, Guyatt GH, Brandt L, Vandvik PO. Introduction to BMJ Rapid Recommendations. BMJ 2016:354:i5191. 10.1136/bmj.i5191. pmid:27680768

44 Guyatt GH, Oxman AD, Vist GE, et al. GRADE Working Group. GRADE: an emerging consensus on rating quality of evidence and strength of recommendations. BMJ 2008;336:924-6. 10.1136/ bmj.39489.470347.AD. pmid:18436948.

Published by the BMJ Publishing Group Limited. For permission to use (where not already granted under a licence) please go to http://group. bmj.com/group/rights-licensing/permissions

This is an Open Access article distributed in accordance with the Creative Commons Attribution Non Commercial (CC BY-NC 4.0) license, which permits others to distribute, remix, adapt, build upon this work non-commercially, and license their derivative works on different terms, provided the original work is properly cited and the use is noncommercial. See: http://creativecommons.org/licenses/by-nc/4.0/

${ }^{1}$ Department of Urology, University of Helsinki and Helsinki University Hospital, 00029 Helsinki, Finland

${ }^{2}$ Department of Public Health, University of Helsinki, 00014 Helsinki, Finland

${ }^{3}$ Urology Section, Minneapolis VAMC and Department of Urology, University of Minnesota, Minneapolis, Minnesota, USA

${ }^{4}$ Department of Health Research Methods, Evidence and Impact, McMaster University, Hamilton, Ontario, Canada

${ }^{5}$ Department of Medicine, Innlandet Hospital Trust-division, Gjøvik, Norway ${ }^{6}$ Department of Research, Netherlands Comprehensive Cancer Organisation (IKNL), Utrecht, The Netherlands.

${ }^{7}$ Cochrane Consumers, London, UK

${ }^{8}$ Citizens United for Evidence-Based Medicine, Virginia, USA

${ }^{9}$ Cameroon Consumer Service Organization (CamCoSO), Bamenda,

Cameroon

${ }^{10}$ Coalition of Civil Society Organizations Cameroon, Bamenda, Cameroon

${ }^{11}$ Department of General Practice and Elderly Medicine, University Medical Centre-Groningen, University of Groningen, Groningen, The Netherlands

${ }^{12}$ Institute of Primary Care, Geneva University Hospitals, Geneva,

Switzerland

${ }^{13}$ Unit of Primary Care Medicine, Faculty of Medicine, University of Geneva, Geneva, Switzerland

${ }^{14}$ Division General Internal Medicine, University Hospitals of Geneva, Geneva, Switzerland

${ }^{15}$ School of Medicine, University of Miyazaki, Miyazaki, Japan

${ }^{16}$ Institute of Primary Health Care (BIHAM), University of Bern, Bern,

Switzerland

${ }^{17}$ Department of Ambulatory Care and Community Medicine, University of Lausanne, Lausanne, Switzerland

${ }^{18}$ The BMJ, London, UK

${ }^{19}$ Division of Clinical Epidemiology, University Hospitals of Geneva, Geneva, Switzerland 